\title{
Computational investigations on port injected DEE in a biogas inducted $\mathrm{HCCl}$ engine
}

\author{
Karthick Jairam, Mohammed Musthafa Feroskhan, Kishorre Annanth Vijayan, and Renganathan Manimaran* \\ School of Mechanical Engineering, Vellore Institute of Technology (VIT) Chennai, Tamilnadu, India
}

Received: 9 January 2021 / Accepted: 28 June 2021

\begin{abstract}
Owing to global climate change and atmospheric pollution, several automobile manufacturing companies look for homogeneously charged engines to satisfy strict emission levels. In the present work, computational fluid dynamics (CFD) investigations have been carried out to showcase the homogeneity of airfuel mixture formation by port fuel injection and manifold fuel injection of a Biogas-Diethyl Ether (DEE) homogeneous charge compression engine (HCCI). The distributions of equivalence ratio based on fuel and the total air-fuel mixture is formulated and found to be in close agreement with the literature. Earlier investigations have shown that the use of biogas as a single fuel causes lower power output compared to other alternative fuels. Hence the present study is planned to use biogas with DEE as an ignition improver via fuel injection systems to find the best suitable fuel injection system. In the mesh independent study, port injection mode is found to perform better against the manifold injection mode when compared with the homogeneity factor. Iso-volumes of excess-air ratio based on biogas, diethyl ether and other variables such as the density, turbulent kinetic energy, turbulent dissipation rate of air-fuel mixture influencing the homogeneity and equivalence ratio are studied for better in-cylinder distribution under the port injection mode.
\end{abstract}

Keywords: Computational fluid dynamics / biogas / ignition improver / engine performance / port injection

\section{Introduction}

With every increase in the number of vehicles on the road, there's an overburden on the petroleum products which are depleting, and hence the requirement for alternate fuels comes into the picture. Biogas has remained globally a renewable energy source and in oil crises, it's going to act as a promising alternative fuel, especially for diesel engines, by substituting for a substantial amount of fossil fuels [1]. The properties of biogas are given in Table 1. Since biogas has a high self-ignition temperature, it can not be inducted alone as a fuel in compression ignition engines and hence Di-Ethyl Ether (DEE) having low auto-ignition and the boiling temperature is chosen as an ignition improver together with lethargic fuels like biogas [2]. The important properties of DEE are given in Table 2.

Homogeneous Charge Compression Ignition (HCCI) combustion is one of all the foremost promising alternatives to SI combustion and CI combustion and can be achieved by premixing the air-fuel mixture and compressing it until the temperature is high enough for autoignition to occur [3]. HCCI has a high potential of achieving good thermal

\footnotetext{
* e-mail: manimaran.r@vit.ac.in
}

efficiency and low $\mathrm{NO} x$ emissions. The fuel is inducted into the manifold together with the air so that it gets mixed with it. The main motive of induction of the fuel into the manifold is for homogenous charge preparation. This homogeneous charge results in high thermal efficiency and low NO$x$ and smoke emissions.

Ryan and Callahan [4] experimentally determined the range of conditions over which homogeneous self-ignition and controlled homogeneous combustion can occur using diesel fuel. He used a port fuel injection (PFI) system to provide diesel into the intake air stream at various inlet air temperatures and compression ratios. The results show that satisfactory power settings are possible with high EGR rates and stoichiometric fuel-air mixtures and concluded that a low compression ratio is most fitted for port injected diesel-fuelled HCCI engine. Garcia et al. [5] investigated the effect of inlet charge temperature, cool EGR, injection timings, and equivalence ratio on the performance of a diesel-fuelled HCCI engine and evaluated the effect of cold EGR on $\mathrm{NO} x$, hydrocarbon (HC), and soot emissions in HCCI combustion mode versus diesel mode and achieved comparatively higher loads by using cool EGR in HCCI mode. Chen et al. [6] introduced dual-fuel HCCI combustion of natural gas with dimethyl ether (DME). They found that by optimizing a proportion of DME and natural gas, 
Table 1. Properties of biogas.

\begin{tabular}{|c|c|}
\hline Property & Value \\
\hline Flammability limit (vol. \% in air)* & $7.5-11.7$ \\
\hline Flame speed $(\mathrm{m} / \mathrm{s})^{*}$ & 21 \\
\hline Stoichiometeric air-fuel ratio ( $\mathrm{kg}$ of air $/ \mathrm{kg}$ of fuel) $)^{\#}$ & 6.05 \\
\hline Density at 1 atm \& $288 \mathrm{~K}\left(\mathrm{~kg} / \mathrm{m}^{3}\right)^{\#}$ & 0.91 \\
\hline Auto-ignition temperature $(\mathrm{K})^{\#}$ & 1087 \\
\hline
\end{tabular}

${ }^{\#}$ For biogas containing $60 \% \mathrm{CH}_{4}$ and $40 \% \mathrm{CO}_{2}$.

${ }^{\$}$ For biogas containing $57.4 \% \mathrm{CH}_{4}$ and $42.1 \% \mathrm{CO}_{2}$.

*For biogas containing $73 \% \mathrm{CH}_{4}$ and $17.4 \% \mathrm{CO}_{2}$.

Table 2. Properties of DEE.

\begin{tabular}{ll}
\hline Properties & Value \\
\hline Formula & $\mathrm{C}_{2} \mathrm{H}_{5} \mathrm{OC}_{2} \mathrm{H}_{5}$ \\
Boiling point $\left({ }^{\circ} \mathrm{C}\right)$ & 35 \\
Cetane number & $>125$ \\
Auto-ignition temperature $\left({ }^{\circ} \mathrm{C}\right)$ & 160 \\
Stoichiometric air-fuel ratio & 11.1 \\
Density $\left(\mathrm{kg} / \mathrm{m}^{3}\right)$ & 712.5 \\
Viscosity $\left(\mathrm{N} \mathrm{s} / \mathrm{m}^{2}\right)$ & $2.3 \times 10^{-4}$ \\
LHV $(\mathrm{MJ} / \mathrm{kg})$ & 33.9 \\
\hline
\end{tabular}

NO $x$ emissions might be lowered to close zero levels. The dual-fuel operation gave higher brake thermal efficiency than that of CI mode. Nathan et al. [7] investigated biogas HCCI combustion with the manifold injection of diesel. They compared the results of biogas-diesel HCCI mode thereupon of biogas-diesel dual fuel mode of operation. This is due to the low volatility and high boiling temperature of diesel; inlet heating was used for correct mixing of diesel with manifold inducted biogas. They concluded that biogas-diesel HCCI operation is superior to the dual-fuel mode of operation during a BMEP range of 2.5-4 bar.

Mobasheri and Peng [8] introduced a modified parameter called the "Homogeneity Factor of in-cylinder charge" (HF) and proposed as a brand new measure in combustion theory to investigate the combustion characteristics and air-fuel mixing process of diesel engines. They studied the effect of split injection parameters including the number of injected mass and also the dwell delay between injection pulses with different EGR rates and hence by optimizing split injection configurations accompanied with appropriate EGR rate, pollutant emissions were decreased and controlled more accurately. Nandha and Abraham [9] proposed a parameter named Degree of Heterogeneity (DOH) to measure the degree of heterogeneity within the mixture, which was shown to yield insight into the physical process under study which was employed. The computational study was carried out to clarify quantitatively the dependence of the mixture formation on the injection timing employing a multidimensional model and therefore the results indicate that there exists an optimum fuel injection system timing to get a maximum degree of homogeneity near TDC. Dimitriou et al. [10] extended the research on air-fuel mixing behavior and the outcome of the mixture quality on the emissions formation and engine performance by developing the modified Homogeneity Factor (HF). Its characteristics under various injection conditions and air swirl motions within the cylinder are investigated with CFD simulation. The results have shown that air-fuel homogeneity is naturally affected by the spatial and temporal fuel distribution within the combustion chamber. Peng et al. [11] explored the Homogeneity Factor (HF) of in-cylinder charge as an effective medium for simplifying the control model structure. Based on multipulse injection, the effects of operating parameters on the Homogeneity Factor were investigated and the results show effects of most operating conditions on the Homogeneity Factor are often analyzed with monomial variations with an ideal correlation between Homogeneity Factor and $50 \%$ burnt location. Ramesh and Mallikarujana [12] attempted to develop methods to evaluate the in-cylinder mixture homogeneity by the CFD analysis. Here, global and local in-cylinder fuel distribution and in-cylinder fuel distribution index are used to evaluate the mixture homogeneity. The results show that the global fuel distribution (GFD) plot helps direct quantitative 


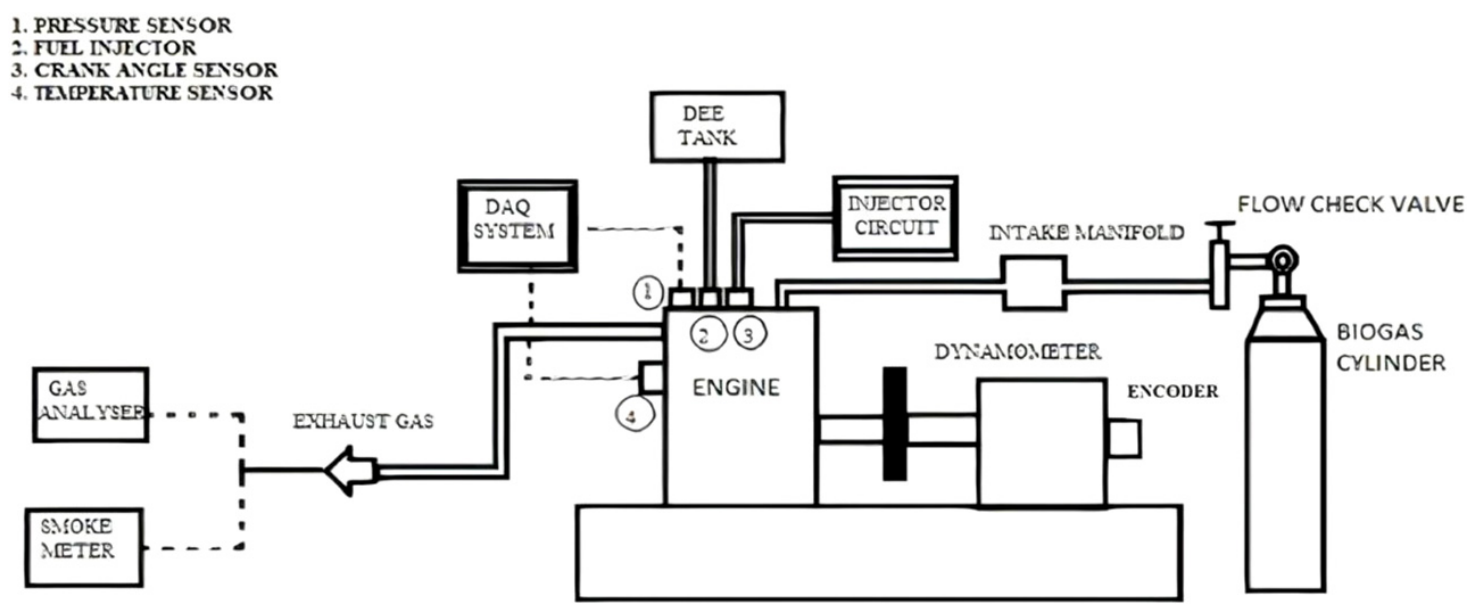

Fig. 1. Schematic of the experimental setup.

assessment of mixture distribution in various ER range. However, the CFD analysis cannot explain the spatial variation of fuel distribution and doesn't provide a mixture of homogeneity on a straightforward scale. Hence the motivation for the present work is to operate a singlecylinder engine in biogas fuelled HCCI mode in a wide load range by using DEE as an ignition improver via both port and manifold injected in the combustion chamber.

The objective of the current study is to find the homogeneity factor and the air-fuel equivalence ratio contours, when biogas-DEE fuel is inducted via both port and manifold injection in a HCCI engine at a constant speed of $1900 \mathrm{rev} / \mathrm{min}$. The fluid parameters such as density, pressure, velocities, turbulent kinetic energy, and turbulent dissipation rate of the air-fuel mixture are analyzed during the suction stroke. The grid and time step independency tests are carried out to find the homogeneity factor and the iso-volumes of equivalence ratio is computed against the port and manifold injection cases.

\section{Experiment and methodology}

A single-cylinder, water-cooled, direct injection CI engine is used for conducting experiments. The engine is coupled to an eddy current dynamometer for loading and measurement purposes. The engine setup diagram can be found in Figure 1. The engine specifications can be found in Table 3. The DEE is stored in an accumulator and is injected into the intake manifold using an injector and hose line of pressure 2 bar. An in-house built electronic circuit is used for controlling the DEE flow rate. The biogas is directly inducted through the intake manifold. The raw biogas is replicated using methane and carbon dioxide in the ratio 65 and 35 respectively. Both of them are separately stored in cylinders and are injected in the 65:35 ratio using flow meters that vary the gases proportions.

The engine is started by using DC motor which is attached to the engine crank shaft with a mechanical clutch. The DEE flow rate is varied with help of a
Table 3. Specifications of engine.

\begin{tabular}{ll}
\hline Parameter & Value \\
\hline Bore and Stroke & $87.5 \mathrm{~mm} \times 80 \mathrm{~mm}$ \\
Cubic capacity & 0.481 Litre \\
Working cycle & 4 -stroke diesel \\
Combustion principle & HCCI \\
Compression ratio & $17: 1$ \\
Peak pressure & $7.5 \mathrm{MPa}$ \\
Maximum power & $6 \mathrm{~kW}$ \\
Maximum torque & $25 \mathrm{Nm}$ \\
Operating speed & $1900 \mathrm{rpm}$ \\
Injection system & Manifold and port injection \\
Injector opening & $2.5 \mathrm{bar}$ \\
pressure (bar) & \\
Fuel injection timing & During suction stroke \\
\hline
\end{tabular}

potentiometer which controls the total time of injection. The RPM of engine is made stable by changing the flow rate of DEE. Once the rpm is stable, the fuel tank, which is placed on a weighing machine measures the mass flow rate of DEE. The amount of flow rate of the biogas is measured using the flow meters. The temperature of the biogas-air mixture is controlled using a heater of honeycomb structure inside the intake manifold. The manometer readings are measured for the flow rate of air. Exhaust gases are analyzed. The variation of load is performed using eddy current dynamo meter. The procedure is repeated by progressively increasing the dynamometer load up to $15 \mathrm{~N}-\mathrm{m}$. The engine performance characteristics and emission characteristics are calculated for various loads.

\section{Computational fluid dynamics methodology}

Investigations on the homogeneity of air-fuel mixture could be better analyzed using computational tools rather than an expensive hardware. In this study, ANSYS FLUENT 
was used to the find the homogeneity factor and the spatial distribution of equivalence rate of air-fuel mixture in the combustion chamber. The cylinder, piston, valves and combustion chamber are mapped to create two types of meshes namely Cartesian mesh and tetrahedral mesh. Boundary conditions are applied appropriately to simulate the physics of air and fuel mixing inside the chamber. The mesh and time independency tests were carried out with different mesh types and different time intervals respectively. The two phase approach was followed for continuous air medium with di-ethyl ether (DEE) injection as dispersed phase using Discrete Phase model (DPM), based on Lagrangian approach whereas Eulerian approach is followed for the continuous phase. Species Transport Model is employed for the induction of methane-air mixture in the combustion chamber. The boundary and initialization conditions were set up based on the experimental conditions. The engine speed was maintained at $1900 \mathrm{rpm}$ and throttle position was closed to analyze the methane-air mixture with DEE spray distribution. To accompany the fluctuations of transport variables, turbulent intensity was allowed a maximum limit of $10 \%$. The biogas and DEE are varied for the same load and approximately the same speed as per the experimental conditions and is injected into the combustion chamber only during suction stroke. The homogeneity factor [9] was calculated based on the equation (1). Contours of the equivalence ratio was also examined and mixture distribution in the cylinder was studied.

$$
\text { Homogeneity factor }=1-\mathrm{DOH}(\theta)
$$

where

$$
\begin{aligned}
\operatorname{DOH}(\theta) & =\sqrt{\sum_{i=0}^{N_{\text {cells }}}\left[\left(\emptyset_{i}-\emptyset_{o}\right)^{2} \delta m_{i}\right] / M} \\
\emptyset_{o} & =\sum_{i=0}^{N_{\text {cells }}}\left[\emptyset_{i} \delta m_{i}\right] / M \\
M & =\sum_{i=0}^{N_{\text {cells } s}} \delta m_{i}
\end{aligned}
$$

where $\emptyset_{i}$ is the equivalence ratio and $\delta m_{i}$ is the mass of the mixture in the computational cell $i, N_{\text {cells }}$ is the total number of computational cells, $\emptyset_{\mathrm{o}}$ is the overall average equivalence ratio of total mixture and $\mathrm{M}$ is the mass of total mixture.

\section{Results and discussions}

\subsection{Experimental results}

\subsubsection{Brake thermal efficiency (BTE)}

Figure 2 demonstrates the variation of brake thermal efficiency with the applied brake power. From the graph (Fig. 2), it is observed that the increase in load escalates BTE. This trend is mainly due to the fact of an increased cylinder temperature and better combustion process at

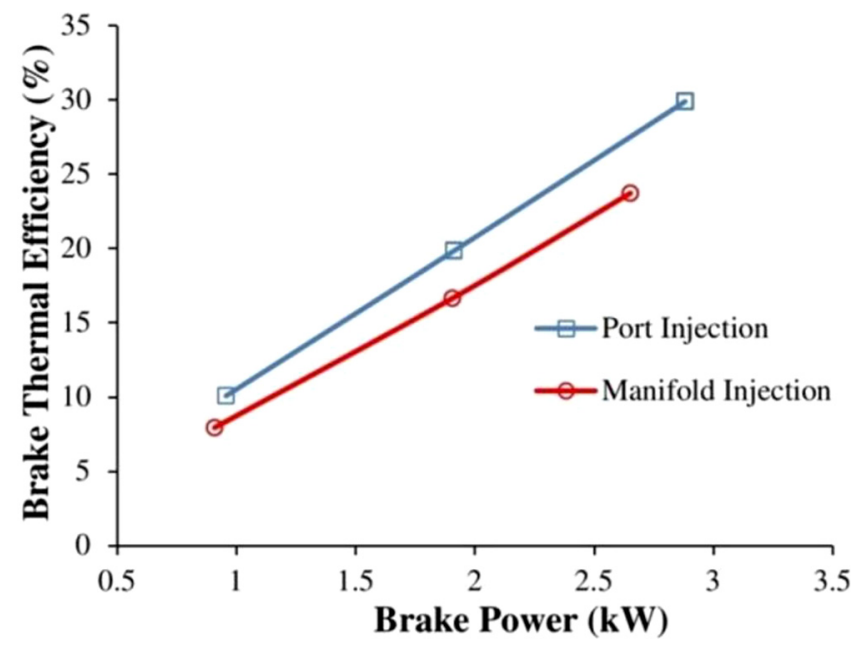

Fig. 2. Effect of port and manifold injections on brake thermal efficiency.

high loads; which in further resulted exothermic reactions that releases huge amount of heat [13]. At $2.7 \mathrm{~kW}$, manifold injection showed an increase of BTE up to $21.8 \%$. At $2.9 \mathrm{~kW}$, port injection showed an increase of BTE up to $28.7 \%$. Brake thermal efficiency of air-fuel mixture when inducted via port injection was better than manifold injection having an increase of $6.9 \%$ BTE compared to manifold injection. The main purpose of this experimentation is to validate the results with the CFD analysis to show port injection is better than manifold injection.

\subsection{Computational Study}

The main aim of the study is to find the homogeneity factor as per equation (1) in port and manifold injection modes. Different mesh type and mesh sizes are chosen and shown in Figure 3. The homogeneity factor is found to arrive for an independent solution in every mesh size and type. Figure 3 shows the homogeneity factor variation with the mesh size for port and manifold injection modes. The mesh independency test was performed for cartesian mesh and tetrahedral cells. The homogeneity factor arrived in the port injection mode with cartesian mesh $(0.74)$ is better when compared with the mesh composed of tetrahedral cells (0.71). Similarly in the mesh independency test for the manifold injection system, the homogeneity factor of cartesian meshing (0.68) is better as compared to the tetrahedral mesh (0.51). The cartesian mesh allows the transport of fluxes in an efficient manner due to orthogonal faces at the boundary between the cells, whereas skewness of the faces decreases the quality of the information in the tetrahedral mesh type. The cartesian mesh of port injection system cases could be automated with the robust technique to create a boundary-conforming mesh even in the complex, curved geometries [14]. Moreover, time steps are also varied in the range from $10^{-4}$ to $10^{-6}$ seconds. Courant number stability condition is maintained to avoid divergence in the homogeneity factor of port injection study. 1 microsecond time interval is included in the simulation for the piston travel from TDC to BDC during 

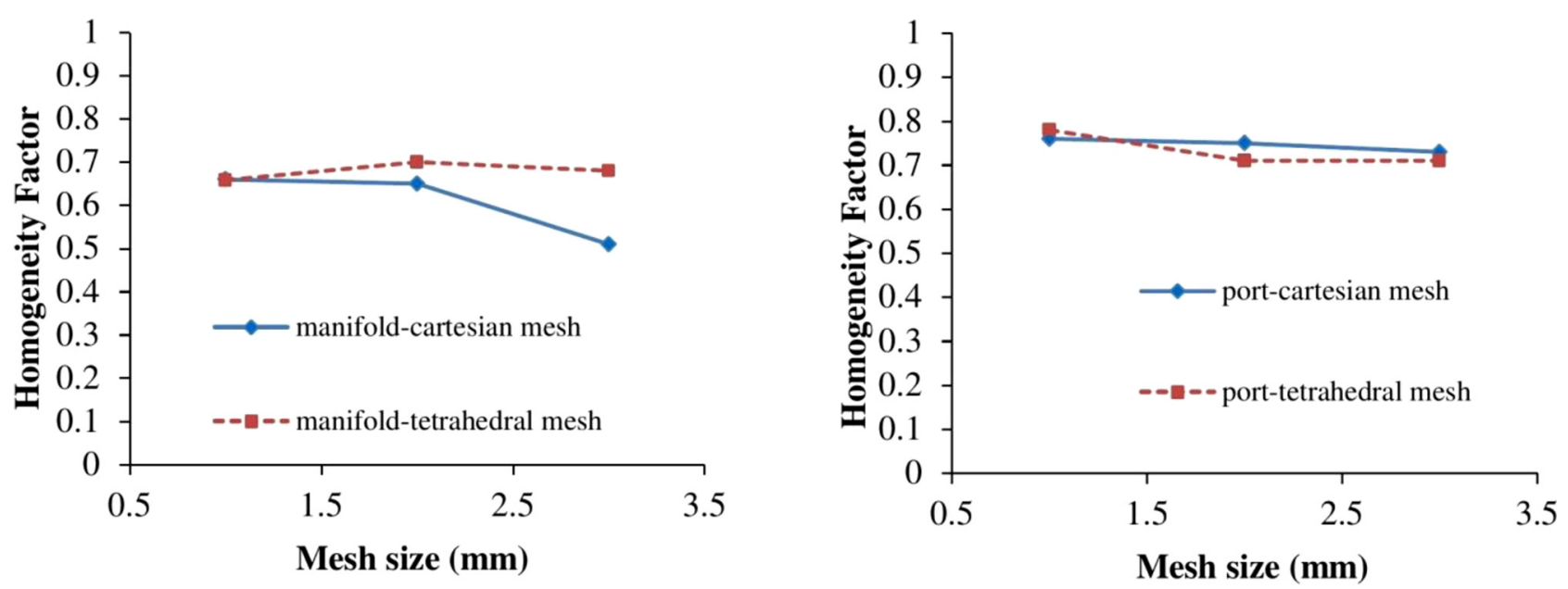

Fig. 3. Effect of cutcell and tetra meshing on homogeneity factor.

the induction stroke. As the homogeneity factor obtained using the port injection system is better as compared to manifold injection, analysis is focused on the port injection mode hereafter.

The study of excess air ratio or air-fuel equivalence ratio is significant if the mixture involves more than a single fuel. Figure $4 \mathrm{a}-\mathrm{f}$ shows the excess air ratio $(\lambda)$ and spatial isovolume distribution of air-fuel mixture when inducted via both port injection and manifold injection in combustion chamber.

$$
\begin{aligned}
\lambda_{B G} & =\frac{M_{A i r}}{M_{B G} * A F_{B G}}, \lambda_{D E E}=\frac{M_{A i r}}{M_{D E E} * A F_{D E E}}, \\
\lambda_{\text {Total }} & =\frac{M_{A i r}}{M_{B G} * A F_{B G}+M_{D E E} * A F_{D E E}}
\end{aligned}
$$

where $M$ refers to mass flow rate, BG refers to Biogas, DEE refers to di-ethyl-ether and $\lambda$ refers to excess air ratio. The above relations are obtained from Sudheesh and Mallikarjuna [2].

The excess air-ratio contours in a slice observed at the normal plane to the centre of cylinder (longitudinal section) are shown in Figure 4a,c,e. The iso-volume distribution in the cylinder is depicted in Figure $4 \mathrm{~b}, \mathrm{~d}, \mathrm{f}$ for different of excess air- ratio as defined before. The biogas is inducted at the intake of manifold, whereas diethyl-ether is injected near the port. The distribution of excess air ratio of biogas ranges from 4.46 to 8.36, as observed in Figure 4a. Similarly the excess air ratio based on di-ethyl-ether is found to vary from 13.5 to 13.7. Overall the total excess air ratio ranges from 3.57 to 6.1 . The isovolumes for the excess air ratio at $6.60,13.55,4.45$ based on the case such as biogas (BG), di-ethyl-ether (DEE) and total (BG and DEE) are shown in Figure $4 \mathrm{~b}, \mathrm{~d}, \mathrm{f}$ respectively. The above said contour slices and iso-volume of excess air ratio give an overall observation for uniform distribution towards mixture preparation inside the cylinder. This information is essential for the preparation of locally fuel-lean in-cylinder mixture at the time of ignition since a sufficient mixing time is available to achieve a large portion of premixed mixture [8].

The density of the air-fuel mixture plays an important role in the combustion mode such as premixed (PCCI)/ stratified (SCCI)/homogeneous charge compression ignition (HCCI). Figure 5 shows an almost uniform density mixture and stratified pressure distribution in the cylinder. This trend is mainly due to higher compression ratios allowed for lower intake charge temperature and higher intake density for higher output during HCCI combustion [15]. Figure 5 shows the stepwise pressure variation of the air-fuel mixture when inducted via port injection in combustion chamber during suction stroke. From Figure 5, it is observed that the maximum pressure reaches at $-200 \mathrm{~Pa}$. The downward movement of piston creates a suction effect at the upper layer in the cylinder. However in the compression stroke, the advancement of start of ignition and combustion can occur before the top dead centre during the power stroke in HCCI combustion. This results in high fuel injection pressure due to incomplete combustion of air-fuel mixture in the combustion chamber [16].

The velocity components of gaseous medium in the cylinder indicate the swirl and tumble motions for the preparation of local mixture. Figure $6 \mathrm{a}-\mathrm{c}$ shows the velocity components along the $\mathrm{X}, \mathrm{Y}, \mathrm{Z}$ directions. The variations of the air-fuel mixture when inducted via port injection in combustion chamber during suction stroke indicates the vertical motion is significant as compared to the horizontal plane motion. Maximum velocity in X, Y and $\mathrm{Z}$ direction was found to be $15 \mathrm{~m} / \mathrm{s}, 11 \mathrm{~m} / \mathrm{s}$ and $25 \mathrm{~m} / \mathrm{s}$ respectively near the valve opening location. This trend is mainly due to high rate of air entrainment and mixing which results in favourable spray structure and better combustion [17].

Turbulence in the cylinder is essential for the shear and split of a ignition improver such as di-ethyl-ether. Figure 7 (left) shows three slices in which the kinetic energy due to turbulence varies by two orders of magnitude. High degree 

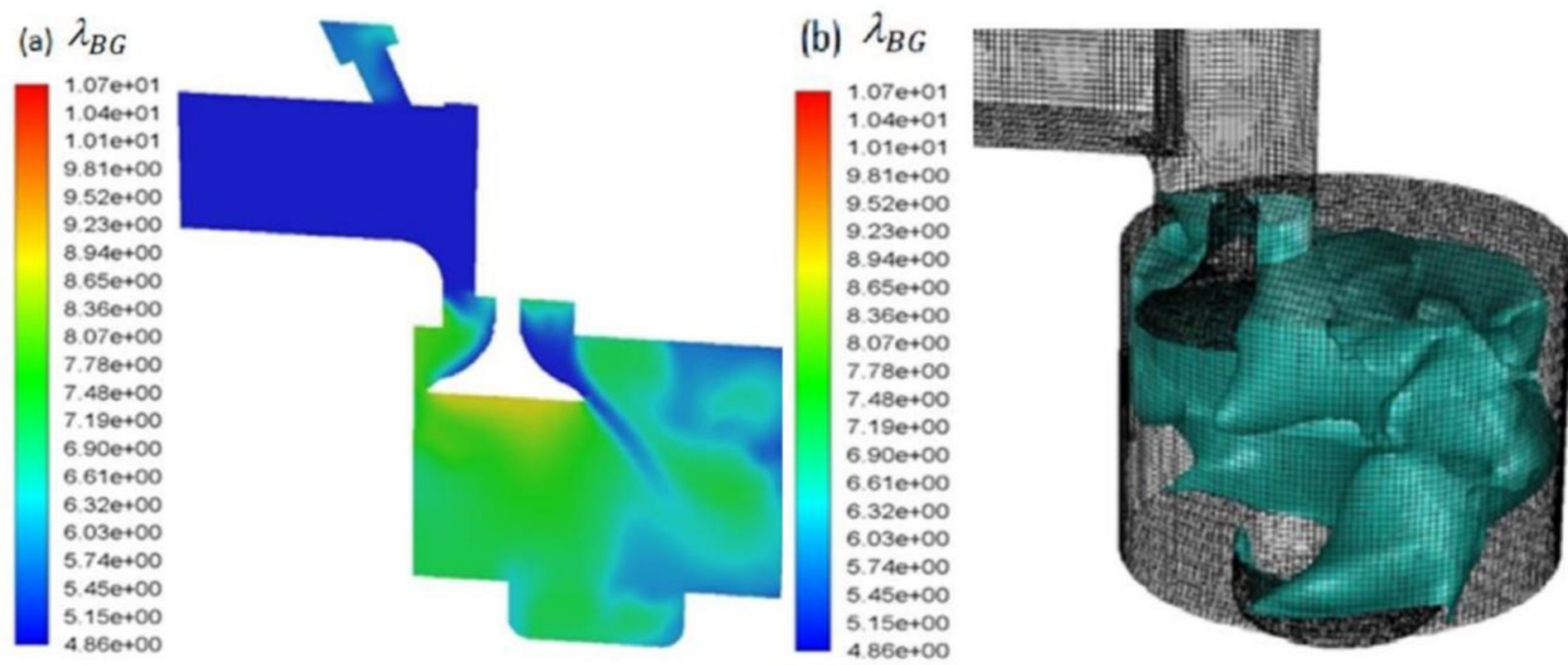

(c) $\lambda_{D E E}$
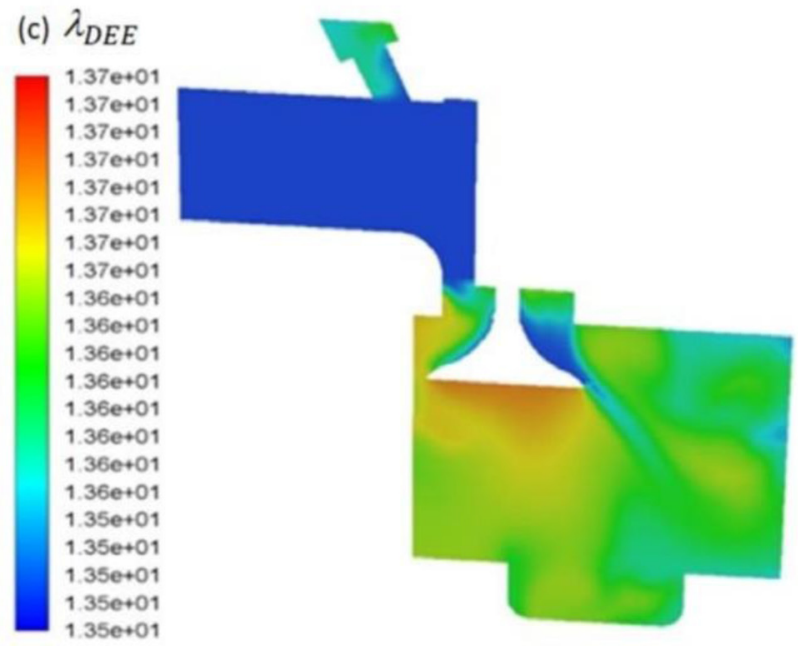

(d) $\lambda_{D E E}$

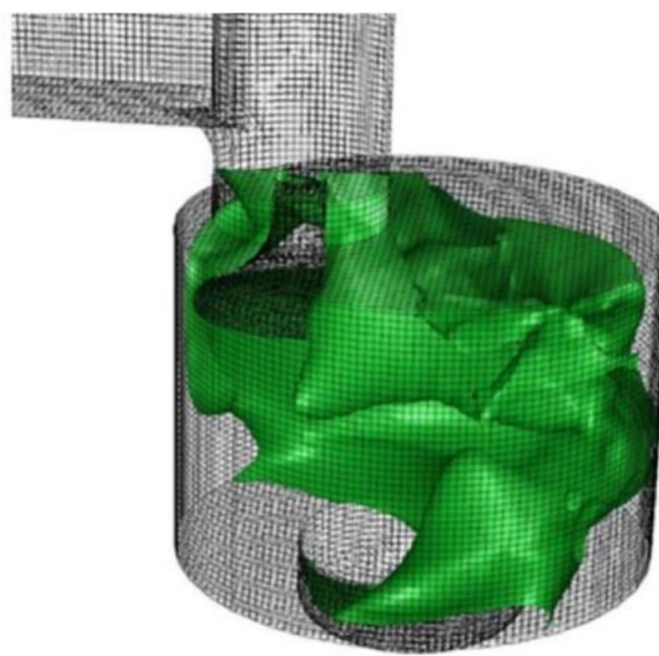

(e) $\lambda_{\text {Total }}$
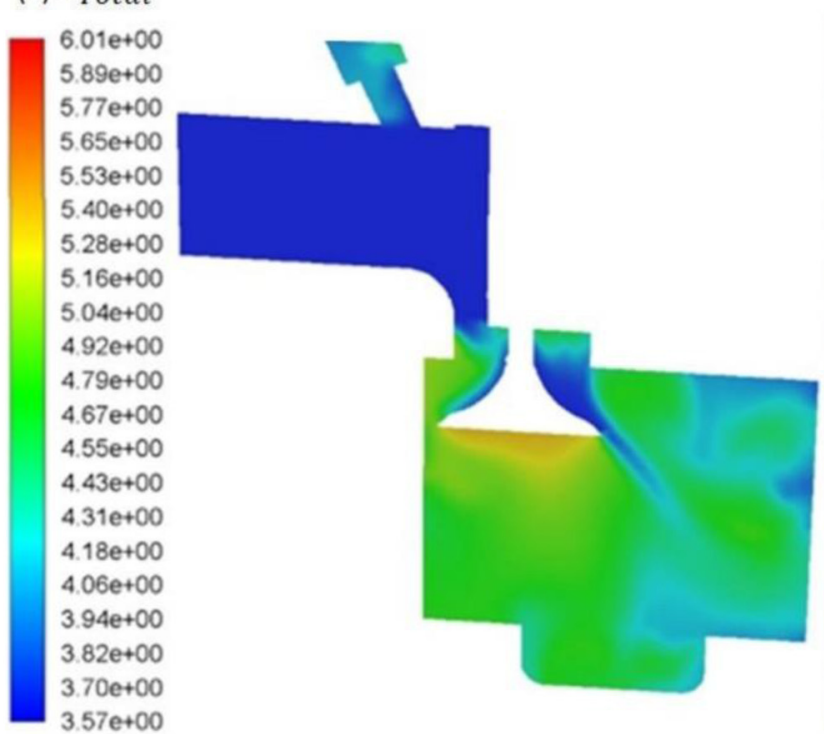

(f) $\lambda_{\text {Total }}$
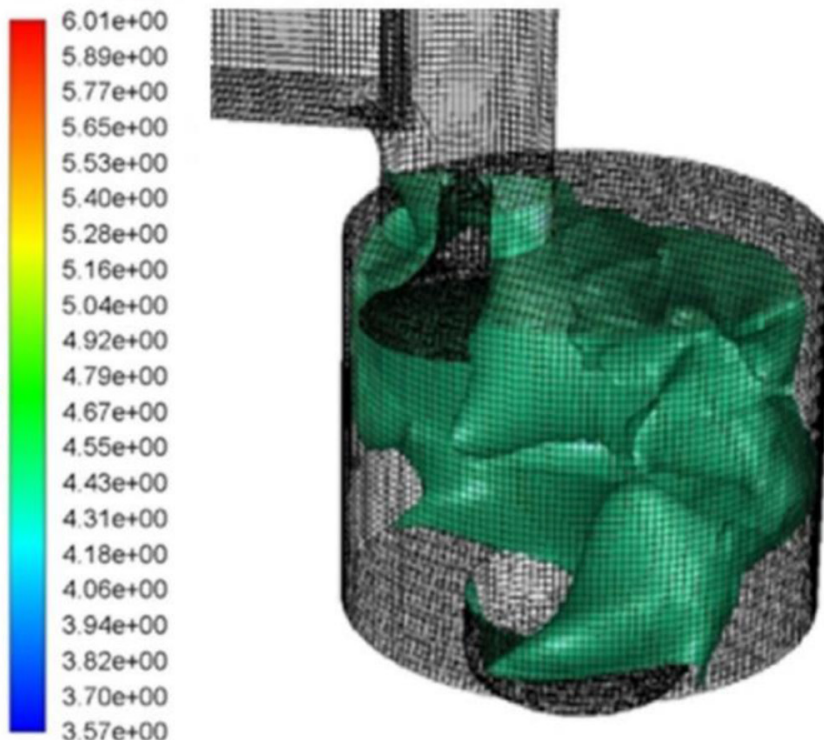

Fig. 4. Slices (left) and iso-volume contours (right) showing the excess air ratio. 


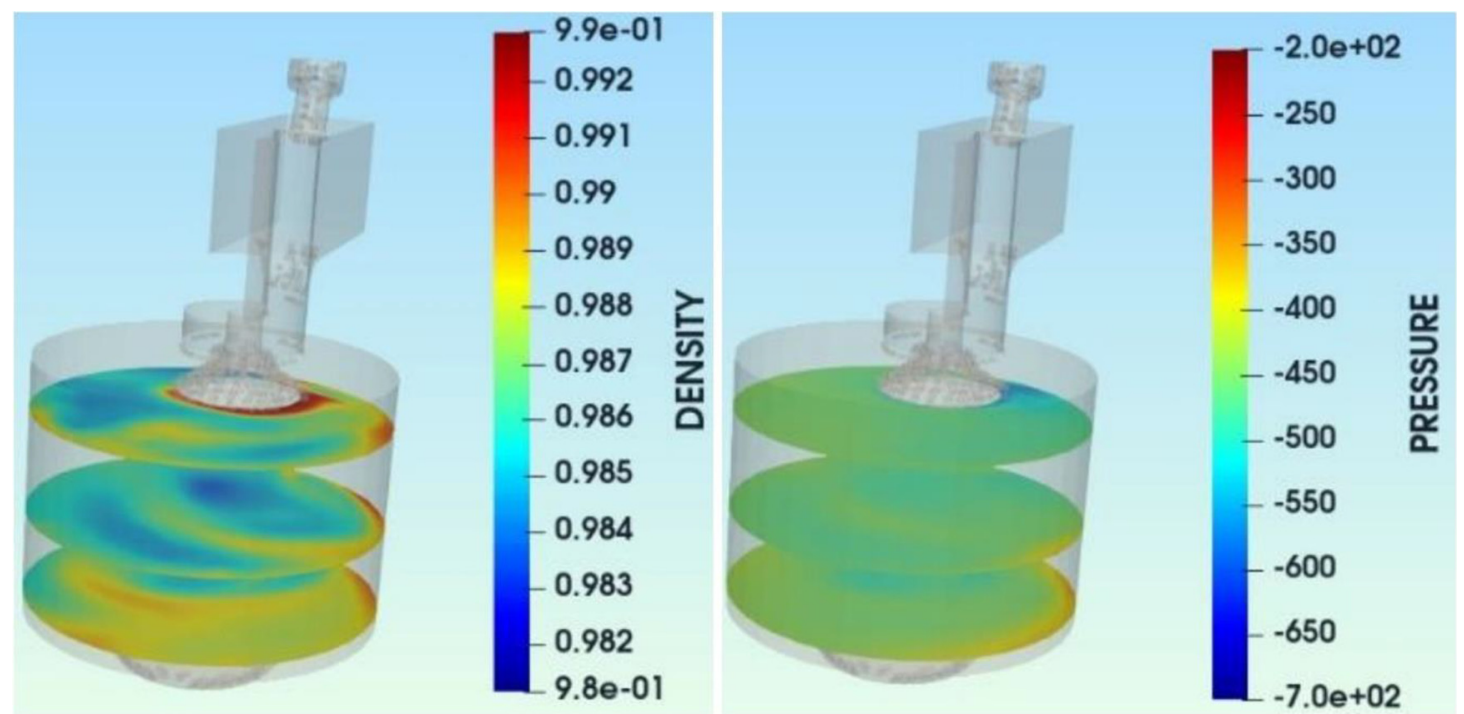

Fig. 5. Density (left) and Pressure (right) distributions of air-fuel mixture in the cylinder.

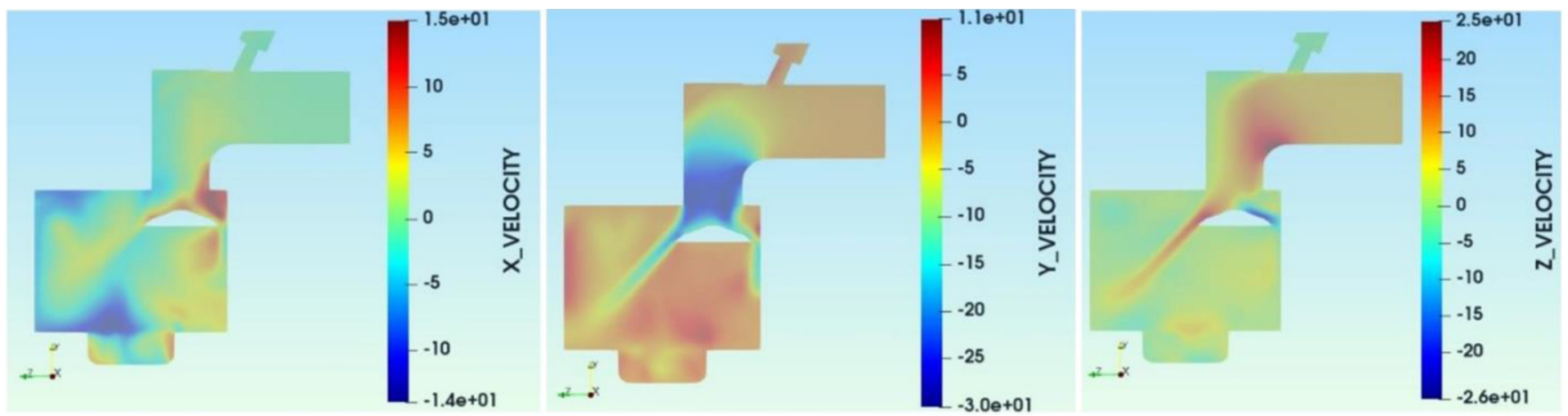

Fig. 6. Velocity component distributions in the cylinder.
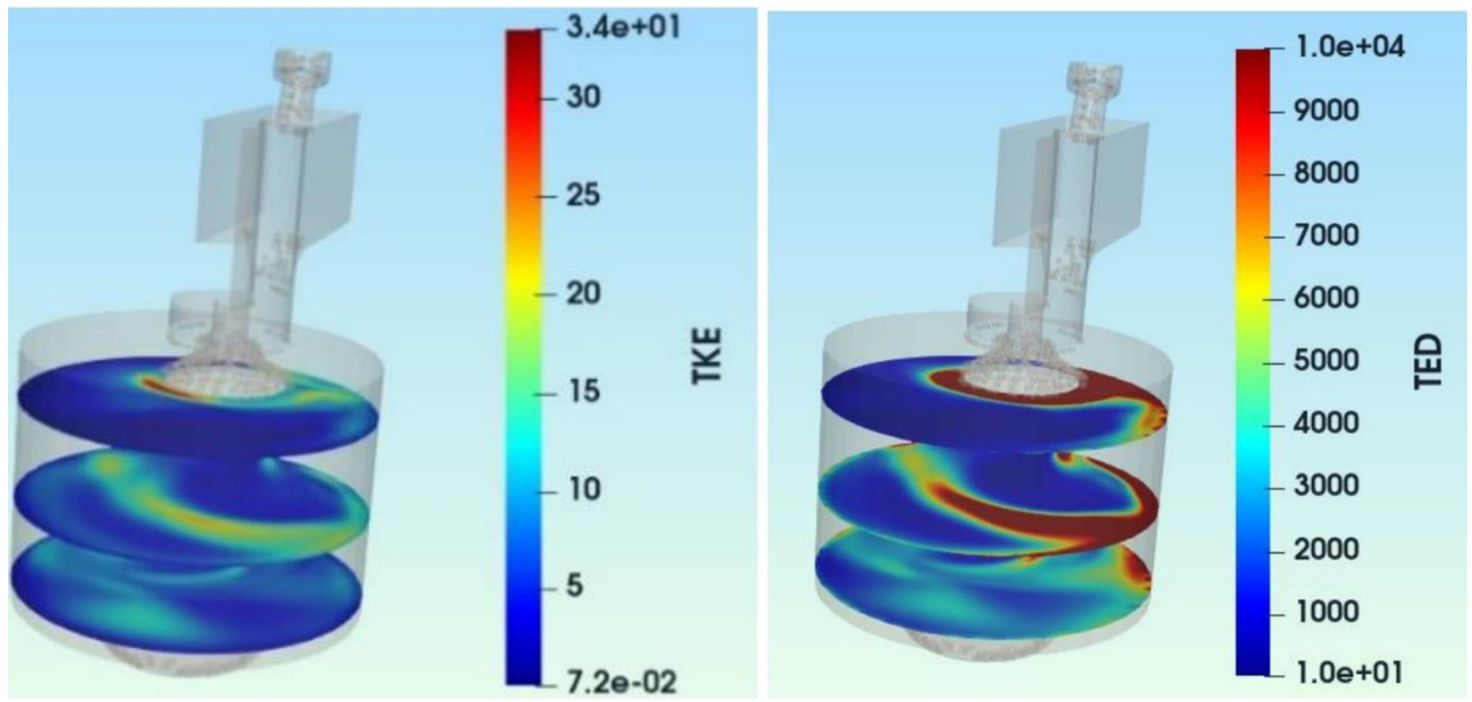

Fig. 7. Turbulent Kinetic Energy (TKE) and Turbulent Energy Dissipation (TED) variation in the cylinder. 
turbulence is noticed near the valve location, which is mostly observed from literature. It is also observed that the turbulent kinetic energy (TKE) was found to lie between the range from 23 to $34 \mathrm{~J} / \mathrm{kg}$. The increase in turbulent kinetic energy is a clear indication of the improved combustion and faster burn time leading towards a more suitable combustion, essential in the HCCI strategy [18]. The dissipation of turbulent energy is shown in contours at the right of Figure 7. It is observed that the maximum value of turbulent energy dissipation reaches close to $10000 \mathrm{~m}^{2} / \mathrm{s}^{3}$, indicating a trend towards achieving the homogeneous charge in the cylinder. This trend is mainly due to the increase in swirl ratio of air-fuel mixture in the combustion chamber up to certain extent $[19,20]$. CFD analysis proves to be fruitful in the simulation of HCCI mixture preparation during the intake stroke. The heat transfer process during the momentum exchange under the wall boundary conditions presents an interesting study as explored by Rajesh and Jacob [21]. The shape deformation modelling and optimisation procedure was applied to a car engine air intake port using CFD solver Fluent [22], as explored in the present study.

\section{Conclusion}

The present study has been carried out to investigate the homogeneity factor by manifold and port injection modes during the induction period and suction stroke. The homogeneity of the air-fuel mixture in the HCCI engine is successfully computed and presents the novelty in this study. The following observations are arrived through both experimental and computational investigations:

- The mesh and time independency tests were performed on different mesh types and different time intervals by varying the mesh counts and time counts respectively in both the manifold and port injection modes. The homogeneity factor of the air-fuel mixture in cartesian meshing system under the port injection mode was $40 \%$ more as compared against the manifold injection with the cartesian mesh.

- On comparison of port fuel-induced injection and manifold fuel-induced injection, the iso-volumes of the air-fuel equivalence ratio contours (i.e. the spatial distribution of air-fuel mixture) was found to be better when inducted via port injection with a variation of $30 \%$ w.r.t manifold mode.

- Different variables such as density, pressure, velocity, turbulent kinetic energy and turbulent energy dissipation rate of the fuel mixture inducted via port injection are analysed during the suction stroke.

- Experimental study was conducted by the same port and manifold injection modes in which the port injection gives rise to $25 \%$ rise in brake thermal efficiency. Computational fluid dynamics studies reveal the incylinder distribution of excess-air ratio and turbulence to provide the insight into the physics and valid reasons for further optimization.

\section{Future scope}

The further improvement in the research can be the addition of turbocharger to achieve more pragmatic results. Also, full cycle CFD analysis including combustion can be studied to compare the onset of maximum incylinder pressure and ensure the effectiveness of combustion. Moreover, studies could be focused on the combustion timing and the engine operating zone for HCCI engines towards reliable and accurate results. Other alternate ignition improvers can be inducted as secondary fuel instead of DEE such that various performance, combustion and emission characteristics can be analyzed and best results can be opted for the respective ignition improver.

\section{References}

1. P.M. Duc, K. Wattanavichien, Study on biogas premixed charge diesel dual fuelled engine, Energy Convers. Manag. 48, 2286-2308 (2007)

2. K. Sudheesh, J.M. Mallikarjuna, Diethyl ether as an ignition improver for biogas homogeneous charge compression ignition (HCCI) operation - an experimental investigation, Energy 35, 3614-3622 (2010)

3. M. Feroskhan, S. Ismail, A review on the purification and use of biogas in compression ignition engines, Int. J. Automot. Mech. Eng. 14, 4383-4400 (2017)

4. T.W. Ryan, T.J. Callahan, Homogeneous charge compression ignition of diesel fuel, SAE Tech Pap, 1996, p. 961160

5. M. Torres García, F. José Jiménez-Espadafor Aguilar, T. Sánchez Lencero, Experimental study of the performances of a modified diesel engine operating in homogeneous charge compression ignition (HCCI) combustion mode versus the original diesel combustion mode, Energy 34, 159-171 (2009)

6. Z. Chen, M. Konno, M. Oguma, T. Yanai, Experimental study of CI natural-gas/DME homogeneous charge engine, SAE Tech Paper, 442-451 (2000)

7. S. Swami Nathan, J.M. Mallikrajuna, A. Ramesh, Homogeneous charge compression ignition versus dual fuelling for utilizing biogas in compression ignition engines, Proc. Inst. Mech. Eng. D 223, 413-422 (2009)

8. R. Mobasheri, Z. Peng, CFD investigation into diesel fuel injection schemes with aid of homogeneity factor, Comput. Fluids 77, 12-23 (2013)

9. K.P. Nandha, J. Abraham, Dependence of fuel-air mixing characteristics on injection timing in an early-injection diesel engine, SAE Tech Pap., 2002, No. 2002-01-0944

10. P. Dimitriou, W. Wang, J. Peng, L. Cheng, M. Wellers, B. Gao, Analysis of diesel engine in-cylinder air-fuel mixing with homogeneity factor: combined effects of pilot injection strategies and air motion, SAE Int. J. Eng. 7, 2045-2060 (2014)

11. Z. Peng, B. Liu, L. Tian, L. Lu, Analysis of homogeneity factor for diesel PCCI combustion control, SAE Tech Pap., 2011, No. 2011-01-1832 
12. N. Ramesh, J.M. Mallikarjuna, Evaluation of in-cylinder mixture homogeneity in a diesel HCCI engine - a CFD analysis, Eng. Sci. Technol. Int. J. 19, 917-925 (2016)

13. D. Barik, S. Murugan, Simultaneous reduction of NOx and smoke in a dual fuel DI diesel engine, Energy Convers. Manag. 84, 217-226 (2014)

14. K.J. Fidkowski, D.L. Darmofal, A triangular cut-cell adaptive method for high-order discretizations of the compressible Navier-Stokes equations, J. Comput. Phys. 225, 1653-1672 (2007)

15. M. Izadi Najafabadi, N. Abdul Aziz, Homogeneous charge compression ignition combustion: challenges and proposed solutions, J. Combust. 2013, 783-789 (2013)

16. E. Mancaruso, B.M. Vaglieco, Optical investigation of the combustion behaviour inside the engine operating in HCCI mode and using alternative diesel fuel, Exp. Therm. Fluid Sci. 34, 346-351 (2010)

17. T. Suzuki, T. Kakegawa, K. Hikino, A. Obata, Development of diesel combustion for commercial vehicles, SAE Tech Pap. 972685 (1997)
18. W.H. Kurniawan, S. Abdullah, K. Sopian, A. Shamsudeen, CFD investigation of fluid flow and turbulence field characteristics in a four-stroke automotive direct injection engine, J. Inst. Eng. 69, 1-12 (2008)

19. A. Viggiano, V. Magi, A comprehensive investigation on the emissions of ethanol HCCI engines, Appl. Energy 93, 277-287 (2012)

20. M.M.S. Ali, S.M.N. Islam, S.M. Sapuan, H.M. Megat, Effects of compression ratio on turbulence kinetic energy and dissipation in the suction stroke of a four stroke internal combustion engine, 4th International Conf Mech Eng. 165-172 (2001)

21. R. Kocheril, J. Elias, CFD simulation for evaluation of optimum heat transfer rate in a heat exchanger of an internal combustion engine, Int. J. Simul. Multidisci. Des. Optim. 11, $6(2020)$

22. J.J. Maisonneuve, F. Pécot, A. Pagès, M. Albertelli, J. Visconti, Comparison of two approaches for the direct optimisation of a car engine intake port, Int. J. Simul. Multidisci. Des. Optim. 2, 37-41 (2008)

Cite this article as: Karthick Jairam, Mohammed Musthafa Feroskhan, Kishorre Annanth Vijayan, Renganathan Manimaran, Computational investigations on port injected DEE in a biogas inducted HCCI engine, Int. J. Simul. Multidisci. Des. Optim. 12, 9 $(2021)$ 